\title{
Sociodemographic predictors of exclusive breast-feeding among low-income women attending a Special Supplemental Nutrition Program for Women, Infants, and Children (WIC) programme
}

\author{
Janine A Rethy ${ }^{1,2}$, Sina Gallo ${ }^{3, *}$, Amara Channell Doig ${ }^{3}$, Jennifer Brady ${ }^{1}$ and \\ David Goodfriend ${ }^{1}$ \\ 'Obesity and Chronic Disease Prevention, Loudoun County Health Department, Leesburg, VA, USA: ${ }^{2}$ Division of \\ Community Pediatrics, MedStar Georgetown University Hospital, Washington, DC, USA: ${ }^{3}$ Department of Nutrition \\ and Food Studies, George Mason University, 4408 Patriot Circle, suite 4100, Fairfax, VA 22030, USA
}

Submitted 17 May 2018: Final revision received 25 0ctober 2018: Accepted 3 January 2019: First published online 26 February 2019

\begin{abstract}
Objective: To describe infant feeding practices and predictors of exclusive breastfeeding among women attending a local Special Supplemental Nutrition Program for Women, Infants, and Children (WIC) programme.

Design: Cross-sectional survey. Outcomes included reported infant feeding practices at 3 and 6 months, timing and reasons for introduction of formula. Descriptive statistics, $\chi^{2}$ tests and logistic regression were used describe the sample and explore relationships between variables.

Setting: Loudoun County, VA, USA.

Subjects: A sample of 190 predominantly Hispanic women attending local WIC clinics.

Results: Overall, $84 \%$ of women reported ever breast-feeding and $61 \%$ of infants received formula in the first few days of life. Mothers who reported on infant feeding practices were less likely to exclusively breast-feed (34v. 45\%) and more likely to provide mixed feeding (50 v. $20 \%)$ at 3 months compared with 6 months, respectively. Significant $(P<0.05)$ predictors of exclusive breast-feeding at 3 months included setting an exclusive breast-feeding goal and completing some high school (compared with completing high school or more). Only education remained a significant predictor of exclusive breast-feeding at 6 months.

Conclusions: A high proportion of women reported giving formula in the first few days of life and many changed from mixed to exclusive breast-feeding or formula by 6 months, suggesting possibly modifiable factors. Further investigation can help drive direct service- as well as policy and systems-based interventions to improve exclusive breast-feeding.
\end{abstract}

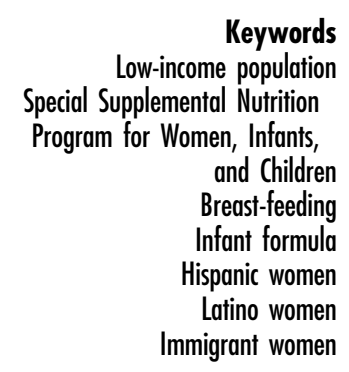

The WHO recommends that infants should be exclusively breast-fed for the first 6 months of life to achieve optimal growth, development and health, with continued breastfeeding along with complementary foods for 2 years ${ }^{(1)}$. Similarly, the American Academy of Pediatrics defines optimal breast-feeding as exclusive breast-feeding for the first 6 months of life, followed by continued breast-feeding with complementary foods up to 1 year or more ${ }^{(2)}$. Breastfeeding protects infants from a variety of health problems $^{(2-4)}$, provides long-term developmental behaviour benefits $^{(5)}$ and improves maternal outcomes ${ }^{(3)}$. Of children born in the USA in 2015 , only $24.9 \%$ of children were breast-fed exclusively for at least 6 months and $17 \cdot 2 \%$ of infants received formula in the first $2 \mathrm{~d}$ of life ${ }^{(6)}$. Although significant progress has been made in recent years toward the Healthy People 2020 goal of $26 \%{ }^{(7)}$, the gap between current practice and optimal breast-feeding may lead to excess morbidity and cost from paediatric and maternal diseases $^{(8)}$.

Racial and ethnic disparities in breast-feeding rates have been reported previously, with ever breast-feeding (defined as any breast milk from birth) higher among White and Hispanic women (85.9 and 84.6\%, respectively) than among Black women (69.4\%; representing rates from 2015) ${ }^{(6)}$. Although breast-feeding initiation rates are similar between White and Hispanic women, discrepancies are apparent at 6 months for exclusivity of breast-feeding (29.5 and $20.9 \%$, respectively) when 
Hispanic women's rates are more similar to those of Black women $(17 \cdot 2 \%)^{(6)}$. This gap becomes wider for Hispanic women as they acculturate to the USA; acculturation is associated with decreased initiation, duration and exclusivity, with each year in the USA associated with a $4 \%$ decrease in ever breast-feeding rates ${ }^{(9,10)}$. Based on hypothetical simulation modelling by Bartick et al., suboptimal breast-feeding in infants of Black and Hispanic women may impose a disproportionately greater burden of infant disease and death as well as non-medical costs compared with non-Hispanic White infants $^{(8)}$.

The Special Supplemental Nutrition Program for Women, Infants, and Children (WIC) is a US federal food assistance programme which targets low-income, nutritionally at-risk pregnant and breast-feeding women and children aged $0-5$ years. WIC participation has been associated with improved infant health outcomes, particularly among a subset of the most disadvantaged ${ }^{(11,12)}$. While some studies have found breast-feeding rates to be lower among WIC-enrolled mothers compared with mothers with similar income not enrolled in $\mathrm{WIC}^{(13,14)}$, others have found more positive results ${ }^{(15)}$. It is possible that inequities in both health-care services and social support for the breastfeeding dyad ${ }^{(16)}$ may account for lower rates of breastfeeding in lower-income and minority populations. However, recent national data show higher ever breast-fed and exclusive breast-feeding rates among WIC-eligible but not enrolled $v$. WIC-enrolled infants, with exclusive rates at 3 and 6 months approaching those of WIC-ineligible infants $^{(17)}$. Possible reasons for lower breast-feeding rates among WIC participants have been suggested, including access to free formula being a disincentive and poor access to lactation support ${ }^{(18,19)}$. Since 2009 , WIC has focused on improving rates through changes in the food packages particularly to incentivize exclusive breast-feeding mothers as well as providing breast pumps and peer support including specialty trained lactation staff ${ }^{(20)}$. A study in California WIC, serving predominantly Hispanic women, found a twofold increase in exclusive breast-feeding at 3 and 6 months after the new food packages were introduced in 2009, even after adjusting for other factors. That study provides additional evidence that extrinsic factors and policies can play a significant role in feeding patterns ${ }^{(21)}$.

The present study aimed to better understand breastfeeding patterns in an understudied population affected by poverty. WIC provides services to a remarkably heterogeneous population of women. Investigating breastfeeding patterns within subgroups of the WIC population is important in order to target effective support. The current paper specifically addresses the following aims among a predominantly immigrant, non-English speaking, Hispanic sample of WIC mothers: (i) determine infant feeding practices; (ii) describe timing and reasons for introduction of formula; and (iii) identify the predictors for exclusive breast-feeding at 3 and 6 months.

\section{Methods}

\section{Design}

The current study was a cross-sectional survey of women attending WIC clinics in Loudoun County, VA, USA. The survey asked questions about one child from each family and some of the questions were retrospective (i.e. infant feeding practices).

\section{Setting}

The WIC programme provides supplemental foods, education/counselling as well as screening/referrals to other health-care professionals. Eligibility includes residency requirements, income $<185 \%$ of the federal poverty line and identified nutritional risk. About $62 \%$ of US infants are eligible for WIC and $80 \%$ of those eligible infants are enrolled in WIC. Food packages for both the mothers and infants are tailored to the age and breast-feeding status of the infant ${ }^{(22)}$. WIC is administered by ninety state agencies in the fifty states, and each agency has some flexibility with food package implementation ${ }^{(23)}$.

\section{Sample}

The target population was a sample of women attending two local WIC clinics between July and August of 2016. Women were eligible to participate in the survey if they were aged 18 years or older (no upper age limit), were able to communicate in either English or Spanish, and if a family member was enrolled in WIC (i.e. mother was pregnant or lactating, child younger than 5 years). Overall 190 women completed the survey representing 10\% of the county WIC population, which was the target sample size for this survey. The participants were informed that the survey was a means to collect de-identified information that would be used to improve the health and services of community members. All participants provided informed consent and completed a self-administered survey on-site using an online survey platform (Qualtrics) on portable tablet devices. All study procedures were approved by both George Mason University and the Virginia Department of Health's Institutional Review Boards. No incentives were provided for completion of the survey.

\section{Survey}

The survey was available in English and Spanish. Both the Loudoun County Health Department and George Mason University Department of Nutrition and Food Studies were involved in the development of the survey and adapted it with input from WIC local agency staff. The majority of WIC participants in this local district report Spanish as their primary language; hence, the survey was provided only in English and Spanish. Both versions of the survey were reviewed and pilot-tested by bilingual WIC staff to ensure consistency and clarity, and study staff were on site to answer questions and administer the survey. All responses 
were anonymous and de-identified. The $\sim 25$ min survey comprised fifty-eight questions and was divided into five main sections: (i) general demographics; (ii) household health and access to assistance programmes; (iii) food and physical activity habits; (iv) maternal supplementation; and (v) infant feeding. The current paper focuses on the results from the infant feeding section.

\section{Measurements}

The questions in the infant feeding section were designed to collect information about the youngest child (see online supplementary material, Supplemental Fig. 1). Questions were at a 5th grade level and responses were limited to closed-ended as suggested for low-literacy populations ${ }^{(24)}$. Child's current age, gestational age as well as medical history were reported. The following demographic variables which were likely to be associated with breast-feeding were included: maternal age, number of children, household size, race and ethnicity, country of birth, education, income and employment status. Language spoken at home was used to describe acculturation ${ }^{(9)}$. Percentage of federal poverty level was calculated using household income and size. Food insecurity was defined based on Hager et al. and as recommended by the American Academy of Pediatrics ${ }^{(25,26)}$. The main outcomes of interest were exclusive breast-feeding at 3 and 6 months postpartum. Participants were asked to best identify their infant feeding for the first 3 and 6 months based on the following categories: (i) breastfed only; (ii) formula-fed only; (iii) mostly breast-fed with some formula-feeding; (iv) mostly formula-fed with some breast-feeding; or (v) other (open-ended response). These definitions were based on WIC food package categories ${ }^{(22)}$ and protocols and recommendations from the American Academy of Pediatrics ${ }^{(27)}$ and the Academy of Breastfeeding Medicine ${ }^{(28)}$. Exclusive breast-feeding was defined as 'breast-fed only'; formula-feeding as 'formula-fed only'; and mixed feeding was defined as 'mostly breast-fed', 'mostly formula-fed' and 'equal amount breast and formula'. Questions on prenatal intention to breast-feed and sources of information about breast-feeding, solid food and formula introduction were also included.

\section{Data analysis}

Descriptive continuous variables for all responses were described as arithmetic mean and standard deviation, or as number and percentage for categorical variables. Characteristics of participants were presented according to infant feeding status; categorical variables were compared using the $\chi^{2}$ test and continuous variables were compared using ANOVA. A sub-sample of participants with children aged $\geq 6$ months at the time of survey completion was included in questions about infant feeding type to enable description of feeding patterns at 3 and 6 months in a similar sample (see online supplementary material, Supplemental Fig. 2). The whole sample was included in all other analyses. Multivariate logistic regression was used to estimate predictors of exclusive breast-feeding at 3 and 6 months and presented as odds ratios and 95\% confidence intervals. Statistical significance was set at $P \leq 0.05$. Data were analysed using the statistical software package IBM SPSS Statistics for Windows version 24.0.

\section{Results}

\section{Participant demographics}

Table 1 describes demographics in the survey sample as well as the county WIC population. There were significant differences for maternal age, ethnicity and education $(P<0.05)$, likely due to inclusion criteria for the survey. The survey sample consisted of $10 \%$ (190 women) of all families enrolled in this local WIC agency at the time of the survey. In brief, the average age of the youngest child in each family was 25.4 months, $85 \%$ were born term and $7 \%$ of the children reported a medical condition (i.e. brain injury, eczema, lactose intolerance, allergies, reflux, speech delay, asthma). The large majority of participants self-identified as Hispanic, of whom $90 \%$ reported Spanish as their primary language. Overall, $81 \%$ were living below the federal poverty line and $46 \%$ reported living with another family or renting space in someone else's home. Food insecurity was high, with 51\% worried about running out of food in the last year.

\section{Infant feeding patterns}

Overall, $84 \%$ of the survey sample reported ever breastfeeding. The sample of mothers who reported on their infant's feeding at 3 months were more likely to provide mixed feeding (50\%) and less likely to exclusively breastfeed (34\%) compared with the sample at 6 months (20 and $45 \%$, respectively; Fig. 1). The majority of mothers (68\%) reported introducing solids at 6 months or older, while $24 \%$ reported introducing solids between 4 and 5 months.

\section{Timing of formula introduction}

Mothers were asked to report timing and reasons for introduction of formula (data not shown). Overall, $91 \%$ of infants received any formula at some point. Of those mothers who gave formula, $18 \%$ did so at the first feeding, and additional $27 \%$ in the days before leaving the hospital, $16 \%$ soon after leaving the hospital, $7 \%$ in the first month, $7 \%$ between 1 and 3 months, $8 \%$ between 3 and 6 months, and $7 \%$ after 6 months. The most common reason mothers gave for introducing formula at all ages was perceived insufficient milk supply followed by going back to work/school.

\section{Sources of breast-feeding information and intention}

The child's paediatrician was the most common source for information and support about breast-feeding ( $n$ 76), 
Table 1 Comparison of demographic characteristics between the survey sample and county WIC populations; survey sample of predominantly Hispanic, low-income women ( $n 190)$ attending local WIC clinics in Loudoun County, VA, USA, July and August 2016

\begin{tabular}{|c|c|c|c|c|}
\hline \multirow[b]{2}{*}{ Characteristic } & \multicolumn{2}{|c|}{$\begin{array}{l}\text { Survey sample } \\
\qquad(n \text { 190)* }\end{array}$} & \multicolumn{2}{|c|}{$\begin{array}{c}\text { County WIC population } \\
(n 2159) \dagger, \ddagger\end{array}$} \\
\hline & Mean or $n$ & SD or $\%$ & Mean or $n$ & SD or $\%$ \\
\hline Maternal age (years), mean and SD & 30.5 & $7 \cdot 2$ & $29 \cdot 2$ & $6 \cdot 0$ \\
\hline Number of family members, mean and SD & 3.9 & 1.6 & 3.7 & 1.4 \\
\hline Number of children, mean and SD & $2 \cdot 3$ & $1 \cdot 3$ & $\mathrm{n} / \mathrm{a}$ & $\mathrm{n} / \mathrm{a}$ \\
\hline \multicolumn{5}{|l|}{ Education, highest level completed, $n$ and $\%$} \\
\hline Elementary school ( $\leq 6$ years of education) & 28 & $15 \cdot 5$ & 18 & $6 \cdot 7$ \\
\hline Some high school (7-11 years of education) & 53 & $29 \cdot 3$ & 27 & $10 \cdot 0$ \\
\hline Completed high school§ & 100 & $55 \cdot 3$ & 224 & $83 \cdot 3$ \\
\hline \multicolumn{5}{|l|}{ Ethnicity, $n$ and \% } \\
\hline Hispanic & 137 & $74 \cdot 1$ & 1310 & $60 \cdot 9$ \\
\hline Non-Hispanic & 48 & $25 \cdot 9$ & 840 & $39 \cdot 1$ \\
\hline \multicolumn{5}{|l|}{ Race, $n$ and \% } \\
\hline Other & 86 & $62 \cdot 3$ & $\mathrm{n} / \mathrm{a}$ & $\mathrm{n} / \mathrm{a}$ \\
\hline White & 23 & $16 \cdot 7$ & $\mathrm{n} / \mathrm{a}$ & $\mathrm{n} / \mathrm{a}$ \\
\hline Black/African American & 19 & 13.8 & $\mathrm{n} / \mathrm{a}$ & $\mathrm{n} / \mathrm{a}$ \\
\hline Asian & 7 & $5 \cdot 1$ & $\mathrm{n} / \mathrm{a}$ & $\mathrm{n} / \mathrm{a}$ \\
\hline American Indian/Alaska Native & 3 & $2 \cdot 2$ & $\mathrm{n} / \mathrm{a}$ & $\mathrm{n} / \mathrm{a}$ \\
\hline \multicolumn{5}{|c|}{ Mother's country of birth (based on UN geographic region classification M49), $n$ and \% } \\
\hline North America $\|$ & 42 & 23.0 & $\mathrm{n} / \mathrm{a}$ & $\mathrm{n} / \mathrm{a}$ \\
\hline Central America and Caribbean (includes Mexico) & 102 & $55 \cdot 7$ & $\mathrm{n} / \mathrm{a}$ & $\mathrm{n} / \mathrm{a}$ \\
\hline South America & 15 & $8 \cdot 2$ & $\mathrm{n} / \mathrm{a}$ & $\mathrm{n} / \mathrm{a}$ \\
\hline Other (Africa, Asia, Europe) & 24 & 13.1 & $\mathrm{n} / \mathrm{a}$ & $\mathrm{n} / \mathrm{a}$ \\
\hline \multicolumn{5}{|l|}{ Income, $n$ and $\%$} \\
\hline$\leq \$$ US $20160 /$ year & 102 & $75 \cdot 6$ & 550 & $69 \cdot 2$ \\
\hline$>$ \$US 20 160/year & 33 & 24.4 & 245 & 30.8 \\
\hline \multicolumn{5}{|c|}{ 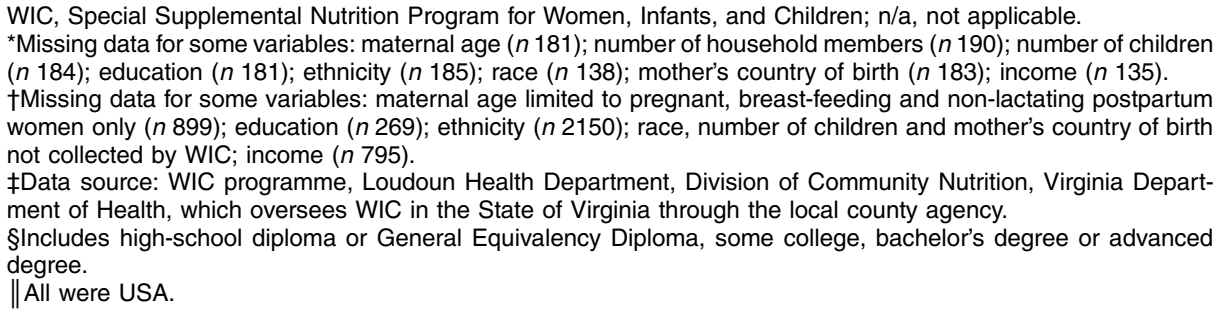 } \\
\hline
\end{tabular}

followed by family members ( $n$ 56), obstetrician/gynaecologist ( $n$ 33), lactation consultant ( $n$ 34), WIC peer counsellor ( $n$ 37), nurse ( $n$ 22), spouse/partner ( $n$ 21), friends ( $n$ 16), social media ( $n$ 12), peers in a breast-feeding support group or class ( $n 6$ ), other (i.e. previous experience; $n 5$ ) or no one ( $n$ 11). Overall, $8.3 \%$ of women reported not planning to breast-feed, $12.4 \%$ planned to breast-fed for less than 3 months, $16.0 \%$ between 3 and 6 months, and $63.3 \%$ for greater than 6 months ( $n$ 169). Overall, $52 \%$ of respondents reported reaching their respective breast-feeding goal and of those whose goal was to exclusively breast-feed, 52\% reported attaining that goal ( $n$ 154).

\section{Predictors of exclusive breast-feeding}

Univariate and multivariate logistic regression models for reported exclusive breast-feeding at 3 and 6 months are presented in Table 2. Education and setting an exclusive breast-feeding goal were significant $(P<0.05)$ predictors of exclusive breast-feeding at 3 months. Trends ( $P$ value between 0.05 and $0 \cdot 1$ ) were observed for receiving breastfeeding advice from a paediatrician and for setting longerduration goals. Setting an exclusive breast-feeding goal predicted a 5.48 times increased likelihood of exclusive breast-feeding at 3 months (95\% CI 1.61, 8.67). Compared with those completing education of high school or greater, not completing high school predicted a 4.00 times increased likelihood of exclusive breast-feeding at 3 months (95\% CI 1.14, 14.10), increasing to a 6.08 times increased likelihood of exclusive breast-feeding at 6 months (95\% CI 1.64, 22.54).

\section{Discussion}

The present study describes infant breast-feeding practices and predictors among a predominantly Hispanic immigrant sample of low-income women attending a local WIC programme. The sample showed low acculturation as indicated by $90 \%$ of Hispanics reporting Spanish as their 
(a)

Mixed feeding

61

$(50 \%)$
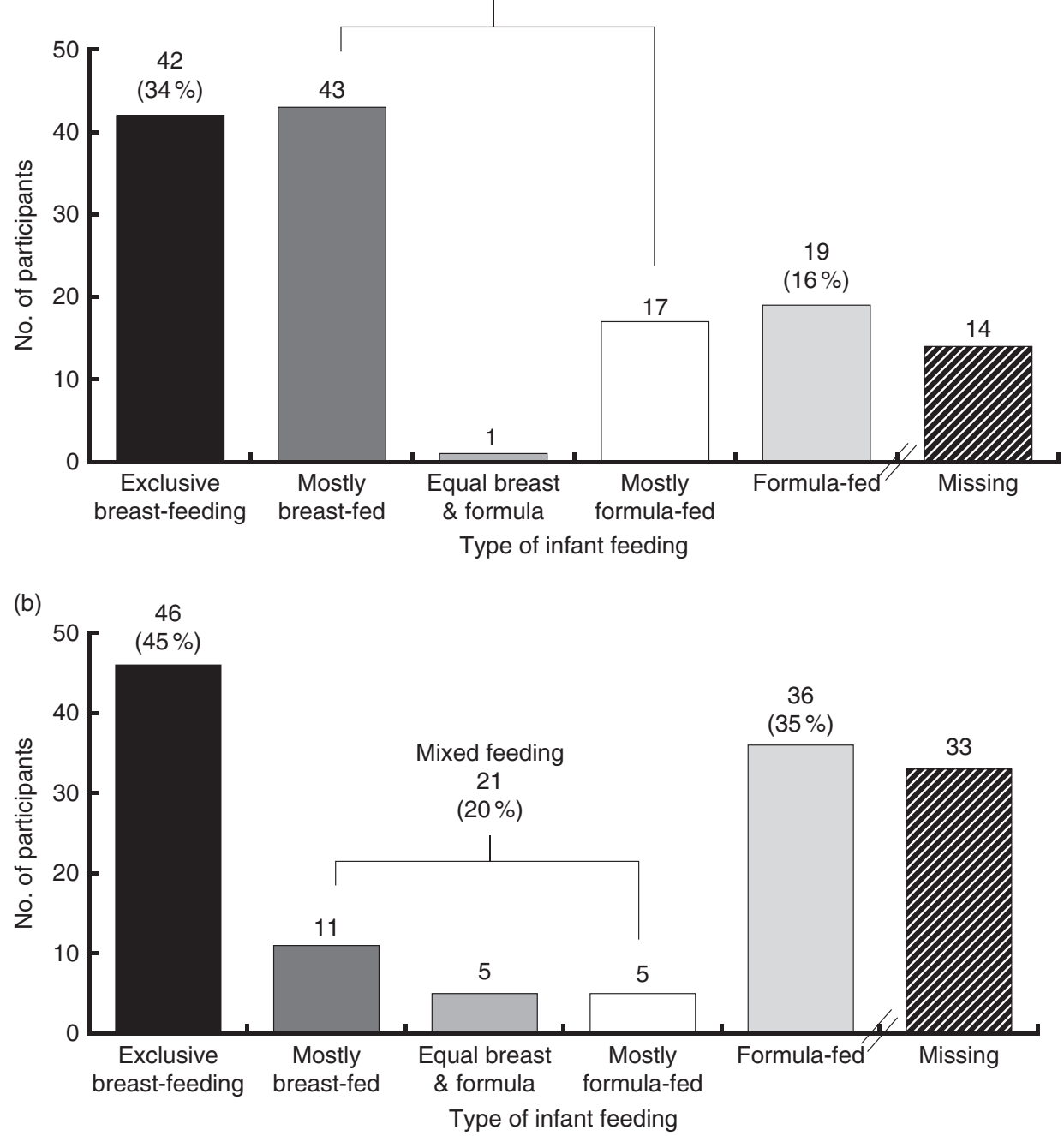

Fig. 1 Number of infants by feeding type at (a) 3 months ( $n$ 122) and (b) 6 months $(n 103)$ in the survey sample of predominantly Hispanic, low-income women $(n 190)$ attending local WIC clinics in Loudoun County, VA, USA, July and August 2016 . Figures show number of missing at each time point; see online supplementary material, Supplemental Fig. 2 for explanation (WIC, Special Supplemental Nutrition Program for Women, Infants, and Children)

primary language. The positive association between lower maternal education and exclusive breast-feeding observed in the current sample is consistent with trends from developing countries ${ }^{(17,29)}$. In comparison to national WIC data, this sample appears to have higher rates of poverty ( $81 \%$ living below the federal poverty line $)^{(30,31)}$ and housing instability ( $46 \%$ living with a family member or renting space).

Overall $61 \%$ of mothers reported giving formula in the first few days of life, $17 \%$ on the first feed and $45 \%$ before they left the hospital, of whom more than half stated insufficient breast milk as the reason. Primary glandular insufficiency, the primary reason for insufficient milk supply, is known to occur in less than $5 \%$ of all women $^{(32)}$. Most early breast-feeding problems can be prevented with early latching within the first hour of life and feeding often on the earliest signs of hunger, or quickly resolved with evidence-based, culturally appropriate support from clinicians ${ }^{(33)}$, including education about normal patterns and volumes of newborn feeds. The American Academy of Pediatrics recommends using formula only when medically indicated ${ }^{(2)}$ and medical indications can occur within the maternity stay, but at much lower rates than the formula introduction which we report in the current study ${ }^{(32,33)}$. The national US rate for formula use during the first $2 \mathrm{~d}$ of life is $17 \%^{(6)}$. Possibilities for this disparity include differences in cultural norms ${ }^{(34)}$, as well as disparities in breast-feeding health services and systems among minority communities ${ }^{(35)}$ and those with limited English proficiency ${ }^{(36)}$. Early introduction of formula is a modifiable risk and can have short-term and long-term health implications. There is extensive evidence that 
Table 2 Logistic regression models for number of infants achieving exclusive breast-feeding at 3 months $\left(n\right.$ 86) and 6 months $(n 70)^{*}$ in the survey sample of predominantly Hispanic, low-income women $(n 190)$ attending local WIC clinics in Loudoun County, VA, USA, July and August 2016

\begin{tabular}{|c|c|c|c|c|c|c|}
\hline \multirow[b]{2}{*}{ Explanatory variable } & \multicolumn{3}{|c|}{ Univariate† } & \multicolumn{3}{|c|}{ Adjusted $\ddagger$} \\
\hline & $\beta$ & OR & $95 \% \mathrm{Cl}$ & $\beta$ & OR & $95 \% \mathrm{Cl}$ \\
\hline \multicolumn{7}{|l|}{ Exclusively breast-fed at 3 months } \\
\hline Maternal age (years) & 0.03 & 1.03 & $0.97,1.10$ & 0.07 & 1.07 & $0.96,1.19$ \\
\hline Number of children & 0.19 & $1 \cdot 21$ & $0.89,1.64$ & 0.11 & $1 \cdot 11$ & $0.62,1.98$ \\
\hline \multicolumn{7}{|l|}{ Education } \\
\hline Completed high school§ & \multicolumn{3}{|c|}{ Ref. } & \multicolumn{3}{|c|}{ Ref. } \\
\hline Elementary school ( $\leq 6$ years of education) & 0.27 & 1.31 & $0.39,4.35$ & -0.41 & 0.66 & $0.11,4.20$ \\
\hline Some high school ( $7-11$ years of education) & 0.70 & $2 \cdot 0$ & $0.88,4.65$ & 1.39 & 4.00 & $1 \cdot 14,14 \cdot 10$ \\
\hline Country of birth North America\| & 0.25 & 1.28 & $0.50,3.26$ & 0.68 & 1.97 & $0.50,7.73$ \\
\hline \multicolumn{7}{|c|}{ Frequency paediatrician discussed breast-feeding } \\
\hline Rarely & \multicolumn{3}{|c|}{ Ref. } & \multicolumn{3}{|c|}{ Ref. } \\
\hline Sometimes & 0.59 & 1.81 & $0.52,6.29$ & 1.22 & 3.39 & $0.57,20.01$ \\
\hline Often & 0.42 & 1.52 & $0.56,4.16$ & 1.21 & 3.35 & $0.82,13.64$ \\
\hline Set exclusivity goal ${ }^{\star \star}$ & 1.23 & 3.42 & $1.43,8.16$ & 1.70 & 5.48 & $1.61,8.67$ \\
\hline \multicolumn{7}{|l|}{ Breast-feeding duration goal $\dagger \dagger$} \\
\hline$<3$ months & \multicolumn{3}{|c|}{ Ref. } & \multicolumn{3}{|c|}{ Ref. } \\
\hline $3-6 n$ & $2 \cdot 38$ & $10 \cdot 77$ & $1 \cdot 18,98.03$ & $2 \cdot 37$ & $10 \cdot 73$ & $0.82,140 \cdot 95$ \\
\hline$>6$ months & $2 \cdot 65$ & $14 \cdot 22$ & $1.82,111.46$ & 1.62 & $5 \cdot 07$ & $0.53,49.00$ \\
\hline Adjusted $R^{2}$ & & $\mathrm{n}$ & & & $33^{\circ}$ & \\
\hline \multicolumn{7}{|l|}{ Exclusively breast-fed at 6 months } \\
\hline Maternal age (years) & -0.00 & 1.00 & 0.94, & -0.04 & \multirow{2}{*}{\multicolumn{2}{|c|}{$\begin{array}{ll}0.96 & 0.87,1.07 \\
1.04 & 0.58,1.88\end{array}$}} \\
\hline Number of children & $0 \cdot 10$ & $1 \cdot 10$ & $0.80,1.51$ & 0.04 & & \\
\hline \multicolumn{7}{|l|}{ Education } \\
\hline Completed high school§ & \multicolumn{3}{|c|}{ Ref. } & \multicolumn{3}{|c|}{ Ref. } \\
\hline Elemen & $1 \cdot 24$ & 3.44 & $0.86,1$ & 1.33 & 3.80 & 0.6 \\
\hline education) & 1.34 & 3.82 & 1.53 & 1.81 & 6.08 & $1 \cdot 64,22 \cdot 54$ \\
\hline Country of birth North America\| & -0.13 & 0.88 & $0.34,2.31$ & 0.50 & 1.65 & $0.45,6.07$ \\
\hline \multicolumn{7}{|c|}{ Frequency paediatrician discussed breast-feeding } \\
\hline Rarely & \multicolumn{3}{|c|}{ Ref. } & \multicolumn{3}{|c|}{ Ref. } \\
\hline Sometimes & 0.83 & $2 \cdot 29$ & 0.59 & 1.83 & $6 \cdot 21$ & 0.87 \\
\hline Often & -0.04 & 0.96 & 0.33 & 0.68 & 1.96 & $0.46,8.39$ \\
\hline Set exclusivity goal ${ }^{\star \star}$ & 0.59 & 1.81 & $0.76,4.30$ & 0.57 & 1.77 & $0.53,5.87$ \\
\hline \multicolumn{7}{|l|}{ Breast-feeding duration goal†† } \\
\hline$<3$ months & \multicolumn{3}{|c|}{ Ref. } & \multicolumn{3}{|c|}{ Ref. } \\
\hline $3-6$ months & 1.90 & $6 \cdot 67$ & $1 \cdot 1$ & 0.99 & $2 \cdot 70$ & 5 \\
\hline$>6$ months & 2.05 & $7 \cdot 74$ & $1.63,36.69$ & 1.14 & 3.13 & $0.48,20 \cdot 26$ \\
\hline Adjusted $R^{2}$ & & & & & 25 & \\
\hline \multicolumn{7}{|c|}{ 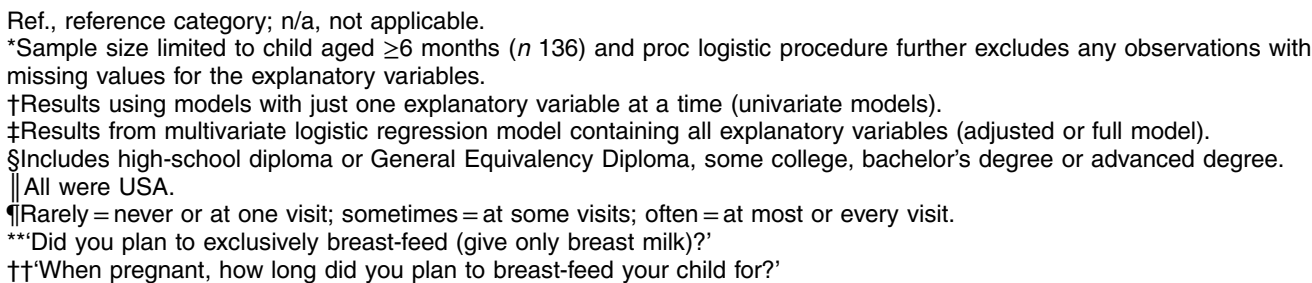 } \\
\hline
\end{tabular}

exclusive breast milk in the first few days after birth plays a critical role in intestinal and immunological health and maturation, which have significant short-term implications for the infant's health and effects that last throughout childhood and even into adulthood.

Interestingly, 6-month exclusive breast-feeding rates in this population were reported as higher than national and state averages for all women and for Hispanic women ${ }^{(6)}$. On closer observation, a high proportion of women in our study reported mixed feeding in earlier months and higher rates of exclusive breast-feeding or exclusive formula at 6 months. The US Department of Agriculture made changes to WIC packages in 2009, including the 6-month package, with the intent of encouraging longer duration of exclusive breast-feeding. The 2009 WIC package changes offer large incentives at 6 months of age for exclusively breast-feeding mothers and babies ${ }^{(22)}$; specifically, the package offers increased foods for the exclusively breastfed infant, and removal of food benefits for the mother of fully or mostly formula-fed infants. Interestingly, another change from 2009 gave WIC agencies the option of not offering any formula in the first month of life, except in special circumstances, to partially breast-feeding infants. This change was recommended as an effort to support mothers in establishing their milk supply and creating and maintaining a successful breast-feeding relationship to 
improve exclusivity and duration. Although not the case for Virginia, $23 \%$ of WIC State agencies ${ }^{(23)}$ including California have implemented this policy and have shown significantly increased early exclusive breast-feeding ${ }^{(21)}$.

Finally, the present study supports the role of healthcare providers in providing breast-feeding counselling; setting breast-feeding goals increased the odds of breastfeeding exclusively at 3 months among this sample. The data also suggest (although not statistically significant, possibly due to a limited sample size) that more frequent breast-feeding counselling from a paediatrician may improve odds of exclusive breast-feeding. While the paediatrician was the primary source of information for breast-feeding, mothers also received breast-feeding information from their family and the WIC peer counsellor; thus, these individuals should also be a target for breast-feeding education interventions.

\section{Strengths and limitations}

Limitations of the current survey include a large reliance on mothers' memories and possibility of recall bias, although previous work found good concordance of maternal recall of breast-feeding up to 6 years later ${ }^{(37)}$. Parenting practices may be a sensitive topic, implying that socially acceptable answers may have resulted. To minimize this bias, the survey was de-identified and selfadministered with limited reliance on interviewer assistance and with efforts to reduce leading. In addition, the large proportion of participants who did not complete high school with possible low literacy may have biased results. The study was likely underpowered and would need to be replicated with a larger sample. Reliability and validity of the survey were not tested. The questionnaire was quite broad in scope, but it did not assess all possible influences on breast-feeding patterns. The results of the present study will guide future studies to further elucidate patterns and influences affecting optimal breast-feeding. An important strength of the survey was that it was anonymous and presented to respondents as independent of WIC services. The survey provides a comprehensive, anonymous assessment of breast-feeding practices among a high-risk group of women, providing good evidence to assess challenges and opportunities, particularly within WIC, more broadly applicable for public health intervention.

\section{Conclusion}

Patterns uncovered in the present study suggest that suboptimal breast-feeding such as early introduction of formula and non-exclusive breast-feeding are impacted by extrinsic factors which are likely modifiable at several points in the health-care continuum. The study highlights the need for a coordinated multisector approach throughout the continuum of care from prenatal services obtained through WIC, prenatal and perinatal and healthcare providers and systems, as well as infant paediatric care and community-based support. Breast-feeding intention was associated with increased duration and exclusivity of breast-feeding, supporting the need for prenatal counselling that emphasizes goal setting based on optimal feeding as well as integrating culturally adapted messaging. To further decrease the very early introduction of formula, it is important that hospitals have policies and practices in place that support latching in the first hour and giving formula only with appropriate counselling or when medically indicated. Additionally, our data corroborate other studies suggesting that WIC breast-feeding packages may influence breast-feeding exclusivity. Considerations for WIC policy and programme change include: earlier and increased education describing the expanded WIC food package for exclusively breast-feeding mothers at 6 months and beyond; and increased focus on intense lactation support in the first weeks, including limiting formula as a part of the WIC package for the first month to special circumstances when indicated. Additional research testing these strategies is warranted to address persisting breast-feeding disparities and increase opportunities for optimal breast-feeding.

\section{Acknowledgements}

Acknowledgements: The authors would like to thank Ms Julizza Canales for help with recruitment and data collection; Ms Canales received financial remuneration for her assistance. They would also like to thank WIC staff and administrators for their support of this study. Finally, the authors thank all the mothers and families who agreed to participate in this study. Financial support: This work was supported by the 'Community Partnerships for Healthy Mothers \& Children' provided by the National WIC Association and Centers for Disease Control and Prevention. The funder had no role in the design, analysis or writing of this article. Conflict of interest: None declared. Author contributions: J.A.R., S.G. and D.G. were involved in study design and ethics approval; A.C.D. and J.B. were involved with data collection; J.A.R., S.G. and A.C.D. completed data analysis; J.A.R., S.G. and A.C.D. wrote the first draft; all authors commented on subsequent drafts of the manuscript. Ethics of human subject participation: This study was conducted according to the guidelines laid down in the Declaration of Helsinki and all procedures involving human subjects were approved by both George Mason University and the Virginia Department of Health's Institutional Review Boards. Written informed consent was obtained from all participants.

\section{Supplementary material}

To view supplementary material for this article, please visit https://doi.org/10.1017/S1368980019000119 


\section{References}

1. World Health Organization \& UNICEF (2003) Global Strategy on Infant and Young Child Feeding. Geneva: WHO.

2. Section on Breastfeeding (2012) Breastfeeding and the use of human milk. Pediatrics 129, e827-e841.

3. Ip S, Chung M, Raman G et al. (2007) Breastfeeding and maternal and infant health outcomes in developed countries. Evid Rep Technol Assess (Full Rep) issue 153, 1-186.

4. Hauck FR, Thompson JMD, Tanabe KO et al. (2011) Breastfeeding and reduced risk of sudden infant death syndrome: a meta-analysis. Pediatrics 128, 103-110.

5. Yorifuji T, Kubo T, Yamakawa M et al. (2014) Breastfeeding and behavioral development: a nationwide longitudinal survey in Japan. J. Pediatr 164, 1019.e3-1025.e3.

6. Division of Nutrition, Physical Activity, and Obesity, National Center for Chronic Disease Prevention and Health Promotion (2018) Breastfeeding Report Card 2018. Atlanta, GA: Centers for Disease Control and Prevention.

7. Office of Disease Prevention and Health Promotion (2010) Healthy People 2020 Objectives: Maternal, Infant, and Child Health. https://www.healthypeople.gov (accessed June 2015).

8. Bartick MC, Jegier BJ, Green BD et al. (2017) Disparities in breastfeeding: impact on maternal and child health outcomes and costs. J Pediatr 181, 49.e6-55.e6.

9. Ahluwalia IB, D'Angelo D, Morrow B et al. (2012) Association between acculturation and breastfeeding among Hispanic women: data from the Pregnancy Risk Assessment and Monitoring System. J Hum Lact 28, 167-173.

10. Gibson-Davis CM \& Brooks-Gunn J (2006) Couples' immigration status and ethnicity as determinants of breastfeeding. Am J Public Health 96, 641-646.

11. Bitler MP \& Currie J (2005) Does WIC work? The effects of WIC on pregnancy and birth outcomes. J Policy Anal Manage 24, 73-91.

12. Black MM, Cutts DB, Frank DA et al. (2004) Special Supplemental Nutrition Program for Women, Infants, and Children participation and infants' growth and health: a multisite surveillance study. Pediatrics 114, 169-176.

13. Jensen E (2012) Participation in the Supplemental Nutrition Program for Women, Infants and Children (WIC) and breastfeeding: national, regional, and state level analyses. Matern Child Health J 16, 624-631.

14. Francescon J, Haile ZT, Kling D et al. (2016) Association between WIC enrollment and exclusive breastfeeding at 3 months postpartum among low-income mothers. I Am Osteopath Assoc 116, 770-779.

15. Gregory EF, Gross SM, Nguyen TQ et al. (2016) WIC participation and breastfeeding at 3 months postpartum. Matern Child Health J 20, 1735-1744.

16. Evans K, Labbok M \& Abrahams SW (2011) WIC and breastfeeding support services: does the mix of services offered vary with race and ethnicity? Breastfeed Med 6, 401-406.

17. Centers for Disease Control and Prevention, US Department of Health and Human Services (2012) Rates of Any and Exclusive Breastfeeding by Socio-demographics among Children Born in 2015. National Immunization Survey. https://www.cdc.gov/breastfeeding/data/nis_data/ rates-any-exclusive-bf-socio-dem-2012.htm (accessed October 2018).

18. Kent G (2006) WIC's promotion of infant formula in the United States. Int Breastfeed J 1, 8.

19. Haughton J, Gregorio D \& Perez-Escamilla R (2010) Factors associated with breastfeeding duration among Connecticut Special Supplemental Nutrition Program for Women,
Infants, and Children (WIC) participants. J Hum Lact 26 , 266-273.

20. Whaley SE, Koleilat M, Whaley M et al. (2012) Impact of policy changes on infant feeding decisions among lowincome women participating in the Special Supplemental Nutrition Program for Women, Infants, and Children. Am J Public Health 102, 2269-2273.

21. Langellier BA, Chaparro MP, Wang MC et al. (2014) The new food package and breastfeeding outcomes among women, infants, and children participants in Los Angeles County. Am J Public Health 104, Suppl. 1, S112-S118.

22. US Department of Agriculture, Food and Nutrition Service (2015) WIC Food Packages - Maximum Monthly Allowances. https://www.fns.usda.gov/wic/wic-food-packages-maximummonthly-allowances (accessed October 2018).

23. Cole N, Jacobson J, Nichols-Barrer I et al. (2011) WIC Food Packages Policy Options Study. Alexandria, VA: US Department of Agriculture, Food and Nutrition Service, Office of Research and Analysis.

24. National Research Council (2001) Studies of Welfare Populations: Data Collection and Research Issues. Washington, DC: The National Academies Press.

25. Hager ER, Quigg AM, Black MM et al. (2010) Development and validity of a 2 -item screen to identify families at risk for food insecurity. Pediatrics 126, e26-e32.

26. Council on Community Pediatrics \& Committee on Nutrition (2015) Promoting food security for all children. Pediatrics 136, e1431-e1438.

27. Schanler RJ, Krebs NF \& Mass SB (editors) (2014) The scope of breastfeeding. In Breastfeeding Handbook for Physicians, 2nd ed., p. 2. Elk Grove Village, IL and Washington, DC: American Academy of Pediatrics and American College of Obstetricians and Gynecologists.

28. Grawey AE, Marinelli KA \& Holmes AV (2013) ABM medicine clinical protocol \#14: breastfeeding-friendly physician's office: optimizing care for infants and children, revised 2013. Breastfeed Med 8, 237-242.

29. Grummer-Strawn LM (1996) The effect of changes in population characteristics on breastfeeding trends in fifteen developing countries. Int J Epidemiol 25, 94-102.

30. US Department of Health and Human Services (2016) Annual Update of the HHS Poverty Guidelines. https:// www.federalregister.gov/documents/2016/01/25/2016-01450/ annual-update-of-the-hhs-poverty-guidelines (accessed October 2018).

31. Johnson B, Thorn B, McGill B et al. (2013) WIC Participant and Program Characteristics 2012. Alexandria, VA: US Department of Agriculture, Food and Nutrition Service.

32. Brownell E, Howard CR, Lawrence RA et al. (2012) Delayed onset lactogenesis II predicts the cessation of any or exclusive breastfeeding. J Pediatr 161, 608-614.

33. Neifert MR (2001) Prevention of breastfeeding tragedies Pediatr Clin North Am 48, 273-297.

34. Valencia AC, Thomson CA, Duncan B et al. (2016) Evaluating Latino WIC mothers' perceptions of infant's healthy growth: a formative assessment. Matern Child Health J 20, $525-533$

35. Jones KM, Power ML, Queenan JT et al. (2015) Racial and ethnic disparities in breastfeeding. Breastfeed Med 10, 186-196.

36. St Fleur R\& Petrova A (2014) Knowledge and perception of breastfeeding practices in Hispanic mothers in association with their preferred language for communication. Breastfeed Med 9, 261-265.

37. Amissah EA, Kancherla V, Ko Y-A et al. (2017) Validation study of maternal recall on breastfeeding duration 6 years after childbirth. J Hum Lact 33, 390-400. 